\title{
Development of technology for automated assembly of aircraft using industrial robotics
}

\author{
P.A. Egorov \\ Aircraft Building Faculty \\ Komsomolsk-on-Amur State University \\ 681013, Komsomolsk-on-Amur, Russian Federation \\ Lainis653@gmail.com
}

\author{
S.V. Belykh \\ Aircraft Building Faculty \\ Komsomolsk-on-Amur State University \\ 681013, Komsomolsk-on-Amur, Russian Federation
}

\author{
Pyae Zone Aung \\ Aircraft Building Faculty \\ Komsomolsk-on-Amur State University \\ 681013, Komsomolsk-on-Amur, Russian Federation
}

\begin{abstract}
The article considers the trend of development of the aircraft building industry in the direction of industrial robotics application. Questions on achieving high assembly accuracy, application of robot manipulators in assembly processes are considered. Intermediate results of calculating the accuracy of the outer contour of the fuselage compartment and the general task of the next stage in the development of the technology were presented for automated assembly of the fuselage compartment. Also, the influence of individual elements of the dimensional chain on the formation of deviations of the external contour of the fuselage compartment collected from the sheet parts is considered.
\end{abstract}

Keywords - robotic assembly; assembly accuracy; industrial robot; automated riveting.

\section{INTRODUCTION}

Assembling the aircraft is a complex and time-consuming process with the use of expensive specialized equipment. Aircraft manufacturers are now more and more interested in investing in automation to increase the flexibility and manufacturability of production with the attendant cost reduction. Scientific and technological progress sets trends for all branches of science and technology. Aircraft construction was no exception. The recent trend is industrial robotics and its application in the production and assembly of aircraft. Despite the growing interest, the use of robots is limited. This is facilitated by the incredible conservatism of the aircraft building industry both in Russia and abroad. Most aircrafts are designed over 10 years ago with obsolete processes to date.

The largest manufacturers of aviation equipment in cooperation with scientific organizations are working on developing technology for the use of industrial robots in the process of assembling aircraft elements [1-4]. In a number of studies, individual tasks of using robots in the assembly process are being solved. In [5, 6], the main aspects of the kinematics of the robot manipulator, which affect the positioning of its operating elements in the performance of individual drilling and riveting operations, are considered. In work [7], a method is given for refining the position of a robot using a laser tracker.

The development of the technology of assembling the elements of the airframe with the use of assembly devices of a simplified design, adapted to the use of industrial robotic manipulators for performing the operations of positioning of individual parts and assemblies, as well as for connecting structural elements, requires a complete revision of all basic rules for the airframe elements in the process assembly. At the same time, it is necessary to develop design requirements that ensure the use of robotic complexes in assembly plants

\section{CAlCUlations OF THE ACCURACY OF THE OUTER CONTOUR OF THE FUSELAGE COMPARTMENT}

The methods of assembly determine the whole complex of technological preparation of production: the choice of the basing scheme and the assembly scheme, the requirements for the technological equipment that ensures the manufacture of the airframe elements with a specified level of accuracy and interchangeability, and also the manufacturing and assembly processes of the tooling.

The method of basing the assembled parts on the basic enclosing elements of the assembly device is traditional in the aircraft industry in order to obtain a high degree of precision in the manufacture of assembly units that are extended to the aerodynamic contours of the airframe (switches, lodges, mock-up elements of the power kit, etc.). However, this method is not applicable in the case of the introduction of automated means of assembly. The need to provide an unobstructed approach to the working elements of automated drilling and riveting devices requires exclusion all basic encapsulating elements from the construction of the assembly device, which requires the development of new methods of basing and assembly rig designs.

Let us consider the influence of individual elements of the dimensional chain on the formation of deviations of the outer contour of the fuselage compartment, assembled from sheet 
parts. In accordance with OST 1 02507-92 «Aircraft subsonic. General requirements for the quality of the external surface», the permissible maximum deviations of the actual position of the outer contour of the fuselage from the theoretical one make up $\Delta_{\Sigma}= \pm 2,0 \mathrm{~mm}$.

Formation of the external contour of the fuselage compartment takes place in the assembly device: the fuselage on the one side and the surface of the mock-up frame are mounted on the lodgments of the mock-up plate; the frame segments of the individual panels are connected along the assembly hole $(\mathrm{AH})$ with the shells. In [10], the main deviations of the individual elements of the dimensional chain for a structure including the segments of frames fabricated by milling are given. From the point of view of technical and economic feasibility, the frame segments are often made by forming methods from a sheet. Let us consider the requirements that must be presented in the stamped frame segment to ensure a given assembly accuracy. The closing link $D_{\Sigma}$ of the main dimensional chain is the distance from the selected point on the outer contour of the fuselage compartment to the aircraft axis (Fig. 1). For this point, the basic dimensional chain is constructed.

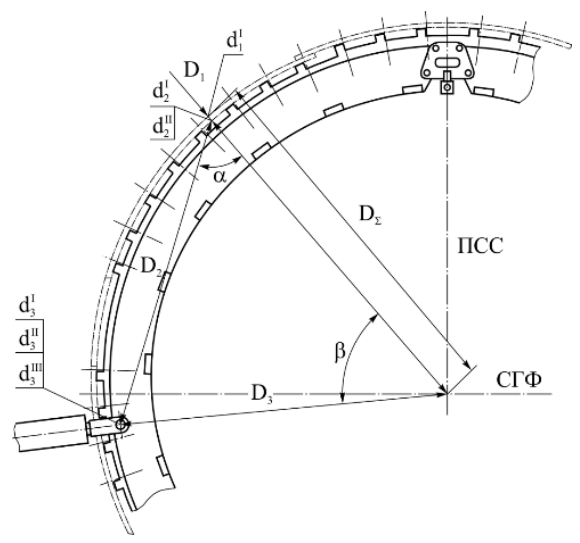

Fig. 1. Scheme of forming the deviations of the outer contour of the fuselage compartment when installing sections on the mock-up frames and breadboard plates

The components of the main dimensional chain are: thickness of the skin $\left(D_{1}\right)$; the size between the point of the outer contour of the frame and the axis of the base hole $(\mathrm{BH})$ in it $\left(D_{2}\right)$; the dimension between the axis of the aircraft and the axis of the aircraft $\left(D_{3}\right)$.

The equation of errors determining the deviation of the outer contour of the fuselage compartment when the sections are mounted on the prototypes and mock-up plates will have the following form:

$$
\delta_{\Sigma}=\delta_{\text {con }}+d_{1}^{I}+d_{2}^{I}+d_{2}^{I I}+d_{3}^{I}+d_{3}^{I I}+d_{3}^{I I}
$$

where:

$\delta_{\text {con }}-$ the error of the outer contour of the compartment, resulting from the deformation of parts after performing riveting $\left(\delta_{\text {con }}=0.1 \delta_{\Sigma}\right)$;

$d_{1}^{I}$ - the error of the outer contour of the section, which occurs when assembling a section in a joint venture; $d_{2}^{I}$ - the error of mutual interconnection of the outer contour and the $\mathrm{BH}$ of the frame;

$d_{2}^{I I}$ - the error of the reciprocal linkage of the $\mathrm{BH}$ in the frame and in the $\mathrm{BH}$ retainers;

$d_{3}^{I}$ - the error in the manufacture of the $\mathrm{BH}$ lock $\left(d_{3}^{I}= \pm 0,05 \mathrm{~mm}\right)$

$d_{3}^{I I}$ - the error that occurs when mounting the $\mathrm{BH}$ lock $\left(d_{3}^{I I}= \pm 0,1 \mathrm{~mm}\right)$

$d_{3}^{I I I}$ - the error caused by the gap between the $\mathrm{BH}$ in the fixator of the assembly device and the pin retainer $\left(d_{3}^{I I I}= \pm 0,03 \mathrm{~mm}\right)$.

Formation of the outer contour of the panel takes place in the assembly device, where the paneling of the panel is mounted on the segments of the frame, made of sheet by forming methods, which in turn are based on the holes in the base elements of the slipway.

Closing link $E_{\Sigma}$ of the main dimension chain is the distance from the selected point on the outer contour of the section to the axis of the aircraft (Fig. 2). For this point, the basic dimensional chain is constructed.

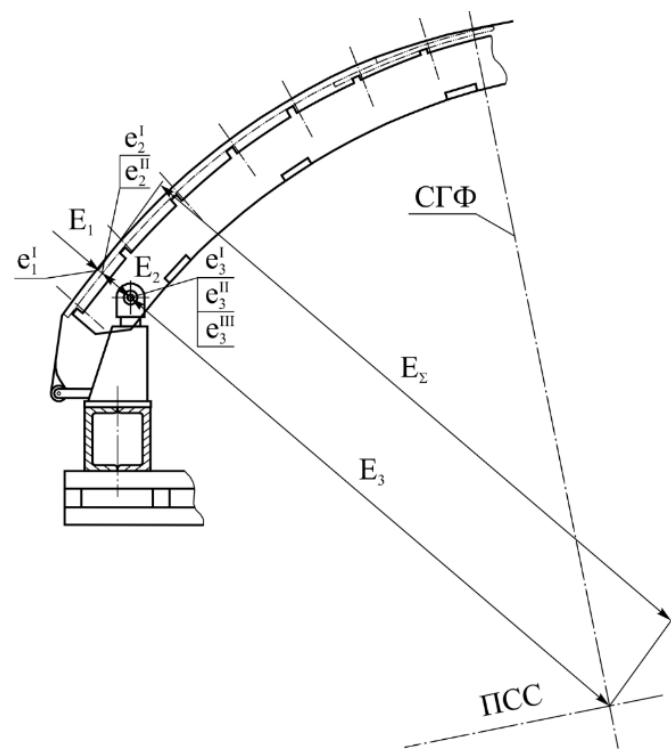

Fig. 2. Scheme for forming the deviation of the contour of the panel

The components of the main dimensional chain are: thickness of the skin $\left(E_{1}\right)$; size between the point of the outer contour of the frame segment and the axis of the $\mathrm{BH}$ in it $\left(\mathrm{E}_{2}\right)$; the dimension between the axis of the aircraft and the axis of the aircraft $\left(E_{3}\right)$.

The equation of errors determining the deviation of the outer contour of the panel during assembly with the basing on the $\mathrm{BH}$ of the assembly device will have the following form:

$$
\delta_{\Sigma}^{\text {panel }}=\delta_{\text {con }}+e_{1}^{I}+e_{2}^{I}+e_{2}^{I I}+e_{3}^{I}+e_{3}^{I I}+e_{3}^{I I I}
$$

where:

$\delta_{\text {con }}$ - the error of the outer contour of the panel, resulting from the deformation of the parts after the riveting $\left(\delta_{\text {con }}=0.3 \delta_{\Sigma}\right)$; $e_{1}^{I}$-the error of the outer contour of the panel, 
arising during assembly;

$e_{2}^{I}-$ the error of interconnection between the external

contour and the $\mathrm{BH}$ segment of the frame;

$e_{2}^{I I}-$ the error of the mutual coordination of the $\mathrm{BH}$

in the frame segment and in the fixators of the $\mathrm{BH}$;

$e_{3}^{I}-$ the error of manufacturing the fixator $\mathrm{BH}$

$\left(e_{3}^{I}= \pm 0,05 \mathrm{~mm}\right)$;

$e_{3}^{I I}$ - the error that occurs when mounting the $\mathrm{BH}$

fixator $\left(e_{3}^{I I}= \pm 0,05 \mathrm{~mm}\right)$;

$e_{3}^{I I I}$ - the error caused by the gap between the $\mathrm{BH}$ in the fixator of the assembly device and the pin retainer $\left(e_{3}^{I I I}= \pm 0,03 \mathrm{~mm}\right)$.

The error in the mutual alignment of the external contour and the $\mathrm{BH}$ of the frame segment $\left(e_{2}^{I}\right)$ for the case of making, a frame segment from a sheet by forming methods is determined by the following errors:

$\delta_{\text {main }}$ - error of manufacturing of an external outline of rigging $\left(\delta_{\text {main }}= \pm 0,1 \mathrm{~mm}\right)$;

$\delta_{f i x}$ - error of fixation, caused by a gap between the diameters of the $\mathrm{BH}$ in the frame segment and the technological bolt in the die tooling $\left(\delta_{\text {fix }}= \pm 0,16 \mathrm{~mm}\right)$;

$f_{1}^{I}$ - the error of the thickness of the sheet preform, which occurs when the frame segment is manufactured $\left(f_{1}^{I}=-0,24 \mathrm{~mm}\right)$;

$f_{1}^{I I}$-error associated with non-fitting of the internal surface of the frame segment to the tooling during the shaping process (Fig. 3);

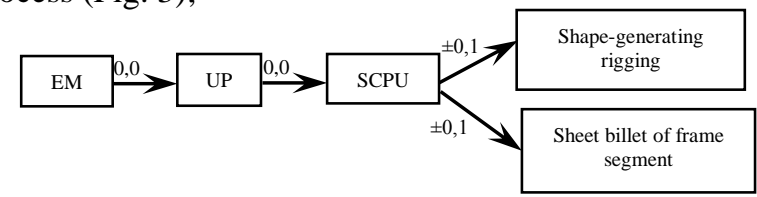

Fig. 3. The linkage scheme for the manufacture of the frame segment

Having made the calculation taking into account the data presented in [10], we obtain the permissible error associated with the non-fitting of the inner surface of the frame segment to the technological equipment during the shaping process, equal to $f_{1}^{I I}=0 \ldots+0,76 \mathrm{~mm}$, which is quite achievable under modern conditions technological possibilities of stamping production.

\section{RESULTS AND DISCUSSIONS}

The theoretical calculations of the accuracy of assembly and the accuracy of manufacturing the fuselage compartment components were based on the specified accuracy according to OST 1 02507-92 «Aircraft subsonic. General requirements for the quality of the external surface» and as a result, the values of deviations that do not exceed the permissible values were obtained. At the next stage, it is planned to obtain experimental data on the accuracy of the assembly. To carry out the experiment, a laboratory is being developed for the automation of assembly and assembly production. The technological equipment, designed taking into account the use of industrial robotic manipulators in the process of assembly, is currently in the process of manufacturing. It consists of a panel assembly stand, a compartment assembly stand and a compartment docking stand with each other. Also, an experimental compartment has been designed, on which the development of the technology under development will take place.

\section{CONCLUSION}

The use of automated means of assembly requires a revision of the approach to basing and linking the assembled nodes. Excluding in the developed technologies traditionally basic elements of assembly devices, it is necessary to lay other bases. It is often difficult to observe the accuracy of the details in such cases, taking into account the human factor - this opens the possibility of using robotic systems that will provide high accuracy of basing. Taking this into account, the coordination of the assembled nodes is simplified by reducing the linking schemes and eliminating the accumulation of errors.

If we are talking about the production of parts by stamping, then analysis shows that with a certain technological level of tooling and production culture it is possible. For this, it is necessary to review both the assembling processes themselves and the procuring processes (designing and manufacturing equipment, parts, manufacturing accuracy).

The preconditions for the use of robotics in the aircraft industry have existed for several years and in the world large companies already use industrial robots at various stages of aircraft production. We need to change the concept of thinking in this area, review existing technologies and processes and create approaches to the implementation of industrial robotics.

\section{References}

[1] Otto J. Bakker, Atanas A. Popov, Svetan M. Ratchev, Variation analysis of automated wing box assembly 50th CIRP Conference on Manufacturing Systems Location: Taichung, TAIWAN publ.: MAY 0305, 2017 MANUFACTURING SYSTEMS 4.0, Series of books: Procedia CIRP, Vol. 63, pp. 406-411, 2017.

[2] N. Fayaweera, P. Webb, Automated assembly of fuselage skin panels ASSEMBLY AUTOMATION, Vol. 27, Issue: 4, pp. 343-355, 2007.

[3] R. Holden, P. Haworth, I. Kendrick, et al. Automated riveting cell for A320 wing panels with improved throughput and reliability (SA2) Technical report, 2007.

[4] Liu Gang, Huan Honglun, Ke Yinglin, "Study on analysis and prediction of riveting assembly variation of aircraft fuselage panel," INTERNATIONAL JOURNAL OF ADVANCED MANUFACTURING TECHNOLOGY, Vol. 75, Issue: 5-8, pp. 9911003, 2014

[5] D. Zhao, Y.B. Bi, Y.L. Ke, "Kinematic modeling and base frame calibration of a dual-machine-based drilling and riveting system for aircraft panel assembly," INTERNATIONAL JOURNAL OF ADVANCED MANUFACTURING TECHNOLOGY, Vol. 9, Issue 5-8, pp. 1873-1884, DOI: 10.1007/s00170-017-0982-th

[6] Nunes Figueira, Jose Augusto; Trabasso, Luis Gonzaga Riveting Induced Deformations on Aircraft Structures JOURNAL OF AIRCRAFT Vol. 52 Issue 6, pp. 2032-2050, 2015.

[7] Aguado Sergio, Samper David, Santolaria Jorge, et al. Identification strategy of error parameter in volumetric error compensation of machine tool based on laser tracker measurements INTERNATIONAL JOURNAL OF MACHINE TOOLS \& MANUFACTURE Vol. 53, Issue 1, pp.160-169, Published: FEB 2012.

[8] Choi Taeyong, Do Hyunmin, Park Dongil, et al. Real-time synchronisation method in multi-robot system ELECTRONICS LETTERS, Vol. 50, Issue: 24 Pages: 1824-U189, 2014. 
[9] R.Kh. Akhatov, K.A. Odnokurtsev, E.V. Zykova, Robotic positioning technology for assembly and installation of structures. Life cycle management systems for aircraft products: current problems, research, implementation experience and development prospects Abstracts of the V International Scientific and Practical Conference, 2016, pp. 20-22.

[10] A.I. Pekarsh, Yu.M. Tarasov, G.A. Krivov, Modern technologies of aggregate-assembly production of aircraft, Moscow: Agraf-press, 2006. 